\title{
Pharmacokinetics of Ganoderic Acids A and F after Oral Administration of Ling Zhi Preparation in Healthy Male Volunteers
}

\author{
Supanimit Teekachunhatean, ${ }^{1,2}$ Sasinun Sadja, ${ }^{1}$ Chadarat Ampasavate, ${ }^{3}$ \\ Natthakarn Chiranthanut, ${ }^{1,2}$ Noppamas Rojanasthien, ${ }^{1}$ and Chaichan Sangdee ${ }^{1}$ \\ ${ }^{1}$ Department of Pharmacology, Faculty of Medicine, Chiang Mai University, Chiang Mai 50200, Thailand \\ ${ }^{2}$ Center of Thai Traditional and Complementary Medicine, Faculty of Medicine, Chiang Mai University, \\ Chiang Mai 50200, Thailand \\ ${ }^{3}$ Department of Pharmaceutical Sciences, Faculty of Pharmacy, Chiang Mai University, \\ Chiang Mai 50200, Thailand \\ Correspondence should be addressed to Supanimit Teekachunhatean, steekach@med.cmu.ac.th
}

Received 14 December 2011; Accepted 30 January 2012

Academic Editor: Yoshiyuki Kimura

Copyright (c) 2012 Supanimit Teekachunhatean et al. This is an open access article distributed under the Creative Commons Attribution License, which permits unrestricted use, distribution, and reproduction in any medium, provided the original work is properly cited.

\begin{abstract}
The objectives of this paper were to evaluate the pharmacokinetics of ganoderic acids A and $\mathrm{F}$ after a single oral dose of the water extract of MG2-strain Ling Zhi (MG2FB-WE) and to assess the influence of food on the pharmacokinetics in 12 healthy male volunteers. This study was a single-dose, open-label, randomized, two-phase crossover study with at least 2 wk washout period. Each subject was randomly assigned to receive a single oral dose of 3,000 mg of MG2FB-WE in granular formulation dissolved in $200 \mathrm{~mL}$ of warm water, either under a fasting condition, or immediately after a standard breakfast (fed condition). Blood samples were collected immediately before and at specific time points until $8 \mathrm{~h}$ after MG2FB-WE administration. Plasma ganoderic acids $\mathrm{A}$ and $\mathrm{F}$ concentrations were determined by using liquid chromatography-mass spectrometry (LC-MS) technique. In conclusion, the pharmacokinetic profile of both ganoderic acids under a fasting condition was characterized by rapid absorption from the gastrointestinal tract $\left(T_{\max }\right.$ at approximately $\left.30 \mathrm{~min}\right)$ and a short elimination half-life $(<40 \mathrm{~min})$. Food significantly decreased $C_{\max }$ and delayed $T_{\max }$, but did not affect the extent of ganoderic acid A absorption. However, concomitant food intake markedly impeded both rate and extent of ganoderic acid $\mathrm{F}$ absorption.
\end{abstract}

\section{Introduction}

The fruiting body of Ganoderma lucidum known as Ling Zhi in China, one of the most famous traditional Chinese medicinal mushroom, has been used extensively for longevity and health promotion in China and other Asian countries for thousands of years [1-3]. Although it is still not clear about Ling Zhi's mechanism on longevity and health promotion, Ling Zhi has been used for the prevention or treatment of various conditions and diseases such as anorexia, neurasthenia, insomnia, migraine, allergy, asthma, bronchitis, gastritis, hepatitis, nephritis, arthritis, lupus erythematosus, diabetes, hypertension, hypercholesterolemia, cardiovascular problems, and cancers [2, 3].
Modern investigations have revealed that Ling Zhi contains a variety of phytochemical compounds. One of the potent biologically active compounds that has been shown to possess diverse and potentially significant pharmacological activities is the bitter triterpenes [2]. Since the first discovery of ganoderic acids A and B, more than 150 types of triterpenes have been isolated from various parts of Ling Zhi $[2,3]$, among which ganoderic acids A and F (Figure 1) have received considerable attention due to their conspicuous pharmacological properties for example, antihypertensive [4], antinociceptive [5], antioxidative [6], farnesyl protein transferase inhibitory [7], and hepatoprotective activities [8, 9], especially anticancer activity [10-13] which is the most attractive character of this medicinal mushroom. Ganoderic 


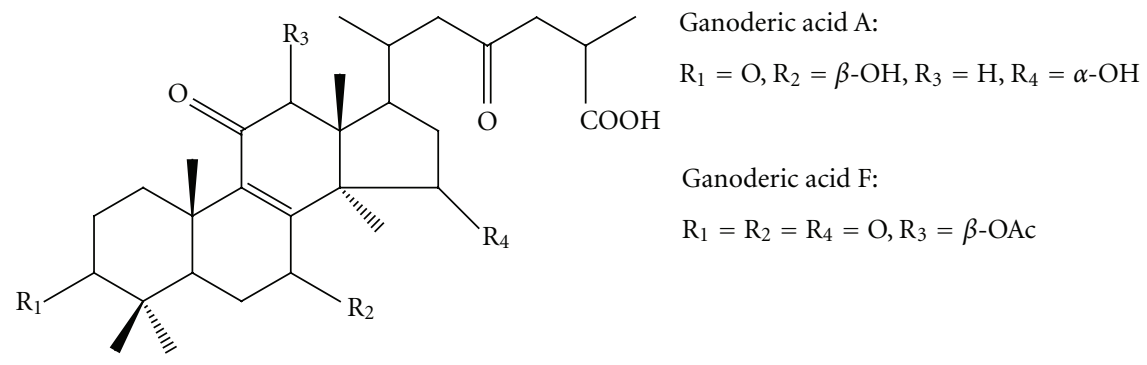

Figure 1: Structures of ganoderic acids A and F.

acid A has been reported to suppress growth and invasion of highly invasive human breast cancer cells via downregulation of expression of cyclin-dependent kinase 4 that regulates cell cycle $G_{1}$ phase progression, and via suppression of secretion of urokinase-type plasminogen activator that implicates in tumor cell invasion and metastasis [12]. On the other hand, ganoderic acid $\mathrm{F}$ has exhibited antitumor and antimetastatic activities through inhibition of angiogenesis [10] and alteration of proteins involving cell proliferation and/or cell death, carcinogenesis, oxidative stress, calcium signaling, and endoplasmic reticulum stress [13].

Although several lines of scientific data from in vitro and in vivo studies supporting Ling Zhi's various pharmacological activities have been extensively documented, the pharmacokinetic study regarding its bioactive compounds in human have not yet been reported. Therefore, the purposes of this paper were to evaluate the pharmacokinetics of ganoderic acids $\mathrm{A}$ and $\mathrm{F}$ and the influence of food on their pharmacokinetics after an oral administration of the water extract of fruiting bodies of MG2-strain Ling Zhi (MG2FB-WE), produced by the Muang Ngai Special Agricultural Project under the patronage of Her Majesty Queen Sirikit, in healthy Thai male volunteers. This water extract of Ling Zhi in granular formulation is being under intensive investigation for its efficacy in the treatment of gynecologic and other cancers in the clinical trials conducted by the Faculty of Medicine, Chiang Mai University (CMU), Thailand.

\section{Materials and Methods}

2.1. Study Design. The study was a single-dose, open-label, randomized, two-phase crossover study with at least a $2 \mathrm{wk}$ washout period. This study was approved by the Human Research Ethics Committee of the Faculty of Medicine, $\mathrm{CMU}$, and complied with the Declaration of Helsinki.

2.2. Subjects. Twelve healthy Thai male subjects, aged between $18-40 \mathrm{y}$ whose body mass index were within the normal range $\left(18-25 \mathrm{~kg} / \mathrm{m}^{2}\right)$, were enrolled into this study. All subjects had to be considered healthy on the basis of their medical history and physical examination. The results of routine laboratory tests including complete blood count, liver function test, blood urea nitrogen, and creatinine had to be within normal limits. Subjects included in the study were given both verbal and written information regarding the nature and purpose of the study. Informed consent was voluntarily obtained from each subject prior to participation in the study. Exclusion criteria were subjects with known hypersensitivity to Ling Zhi, known medical history of neurological, pulmonary, kidney, liver, cardiovascular diseases, or malignancy, recent cigarette smoking within the previous 3 months, use of alcohol, substance abuse, any Ling Zhi preparation, as well as other medications (except acetaminophen) within the previous 1 month.

2.3. Dosage and Administration. Eligible subjects were admitted to the Clinical Pharmacology Unit, Faculty of Medicine, CMU, at 6:30 AM after an overnight fast of at least $8 \mathrm{~h}$. Each subject was randomized to receive a single oral dose of MG2FB-WE either under a fasting condition, or immediately after a Melander type standard breakfast (fed condition). The standard breakfast consists of $150 \mathrm{~mL}$ semiskimmed milk, $100 \mathrm{~mL}$ orange juice, 1 hard-boiled egg, 2 pieces of whole wheat bread, $5 \mathrm{~g}$ margarine, $20 \mathrm{~g}$ orange marmalade and $20 \mathrm{~g}$ hard cheese [14]. The $3,000 \mathrm{mg}$ of MG2FB-WE in granular formulation containing 1,417.80 \pm $40.74 \mu \mathrm{g} / \mathrm{g}$ of ganoderic acid A and $224.15 \pm 8.02 \mu \mathrm{g} / \mathrm{g}$ of ganoderic acid $\mathrm{F}$ was dissolved in $200 \mathrm{~mL}$ of warm water before oral administration. All subjects were instructed to remain upright without intake of any food or beverage for $2 \mathrm{~h}$ after Ling Zhi administration. Water and lunch were served at 2 and $4 \mathrm{~h}$ after dosing, respectively. Serial blood samples were collected at different time points as described below. After blood sample collection at $8 \mathrm{~h}$ after dose, all subjects were discharged from the Clinical Pharmacology Unit. After a washout period of at least $2 \mathrm{wk}$, the subjects were crossed over to receive the same oral dose of Ling Zhi preparation after an alternative (fasting or fed) condition. The blood sample collection and other study conditions in the 2nd study period were as same as the previous study period. An identical meal and fluid were served on both study days. All subjects were instructed to avoid consumption of Ling Zhi or any Ling Zhi preparation throughout the study period.

2.4. Blood Sample Collection. Serial blood sample collections (10 mL each) were obtained before oral administration of the Ling Zhi preparation, and at 5, 10, 15, 30, and $45 \mathrm{~min}$, then at $1,1.5,2,2.5,3,3.5,4,5,6$, and $8 \mathrm{~h}$, respectively, after dosing for the determination of the plasma concentration of ganoderic acids A and F. The blood samples were obtained 
from the forearm by venipuncture through an indwelling intravenous catheter and collected into heparinized vacutainers. The blood collecting tubes were centrifuged at $1,040 \mathrm{~g}$ for $15 \mathrm{~min}$ at $4^{\circ} \mathrm{C}$ and the plasma was then separated and frozen at $-20^{\circ} \mathrm{C}$ until analysis.

\subsection{Determination of Ganoderic Acids A and F Concentrations}

2.5.1. Sample Preparation. The plasma sample extraction for the quantitative determination of ganoderic acids $\mathrm{A}$ and $\mathrm{F}$ was performed by using protein precipitation method. Concisely, $250 \mu \mathrm{L}$ of each plasma sample was spiked with $25 \mu \mathrm{L}$ of internal standard (IS, $2.50 \mathrm{ng} / \mathrm{mL}$ of cortisone 21 acetate), and subsequently deproteinated by mixing with $500 \mu \mathrm{L}$ of $1 \%$ acetic acid in $50 \%$ methanol/acetonitrile and then kept at room temperature for $20 \mathrm{~min}$. The proteins in the plasma sample were separated by centrifuge at $18,620 \mathrm{~g}$ for $10 \mathrm{~min}$ at room temperature. Thereafter, an aliquot of the supernatant was removed and evaporated to dryness by the concentrator at $60^{\circ} \mathrm{C}$ for $1.5 \mathrm{~h}$. The residues were then dissolved in $50 \mu \mathrm{L}$ of mobile phase and a $15 \mu \mathrm{L}$ of the sample was injected into the LC-MS system. LC-MS chromatogram of plasma containing ganoderic acids $\mathrm{A}$ and $\mathrm{F}$ and IS is presented in Figure 2. Plasma concentration of ganoderic acids $\mathrm{A}$ and $\mathrm{F}$ were determined by using a calibration curve of the peak area ratios of each ganoderic acid and IS, versus respective ganoderic acid concentrations with the use of linear regression analysis (correlation coefficient value $\geq 0.99$ ).

2.5.2. LC-MS System and Conditions. All analyses were performed using an Agilent 1100 series LC system coupled with MSD single quadrupole mass spectrometer (Agilent LC/MSD API-Electrospray) system. The sample were separated using a Zorbax SB- $\mathrm{C}_{18}$ analytical column $(4.6 \times$ $150 \mathrm{~mm}, 5 \mu \mathrm{m}$ ) from Agilent technologies in a $20 \mathrm{~min}$ runtime. Solvent A consisted of $10 \mathrm{mM}$ of ammonium formate ( $\mathrm{pH} 4.00$ ), whereas solvent $\mathrm{B}$ was acetonitrile. The mobile phase was delivered in a constant ratio of solvent $\mathrm{A}: \mathrm{B}$ $(40: 60, \mathrm{v} / \mathrm{v})$ at flow rate of $1.0 \mathrm{~mL} / \mathrm{min}$. The MS was equipped with an electrospray ionization interface and operated in positive ion mode in mass-to-charge radios of 499.40 and $555.30 \mathrm{~m} / \mathrm{z}$ for ganoderic acid A, 571.30 and $572.30 \mathrm{~m} / \mathrm{z}$ for ganoderic acid $\mathrm{F}$ and 403.20 and $441.20 \mathrm{~m} / \mathrm{z}$ for IS. The gas temperature was $350^{\circ} \mathrm{C}$, drying gas $13 \mathrm{~L} / \mathrm{min}$, and nebulizer pressure $50 \mathrm{psi}$.

2.6. Assay Validation. The assay validation was performed following the US Food and Drug Administration guidance for bioanalytical method validation [15]. The LLOQ value of both ganoderic acids $\mathrm{A}$ and $\mathrm{F}$ under the LC-MS condition used in this study was $0.50 \mathrm{ng} / \mathrm{mL}$. The percentages of coefficient of variation (\% CV) at LLOQ concentration of ganoderic acids A and F were 5.92\% and $15.90 \%$, respectively, whereas the accuracy at this concentration were $113.50 \%$ and $114.95 \%$, respectively. The mean \% CV of intraday precision of ganoderic acids $\mathrm{A}$ and $\mathrm{F}$ were $3.48 \%$ and $3.62 \%$, respectively, whereas, those of interday of ganoderic

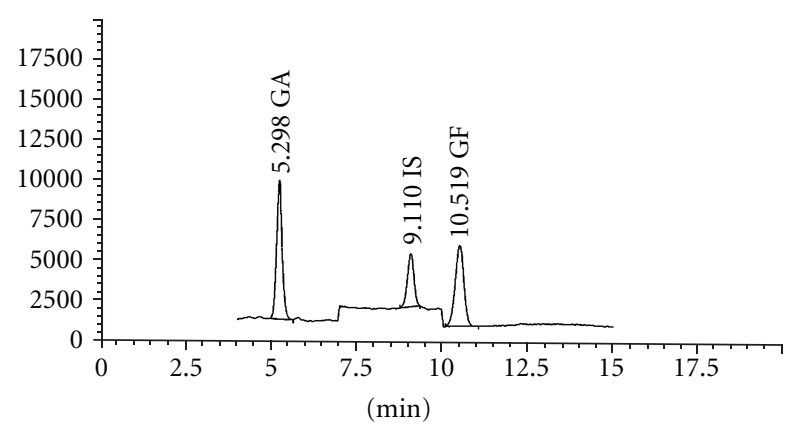

FIGURE 2: LC-MS chromatogram of plasma containing $18.00 \mathrm{ng} / \mathrm{mL}$ of ganoderic acids A (GA, retention time $=5.298 \mathrm{~min}$ ) and $\mathrm{F}(\mathrm{GF}$, retention time $=10.519 \mathrm{~min}$ ) as well as $2.50 \mathrm{ng} / \mathrm{mL}$ of IS (retention time $=9.110 \mathrm{~min})$.

acids $\mathrm{A}$ and $\mathrm{F}$ were $3.64 \%$ and $3.17 \%$, respectively. Likewise, the mean accuracy of intraday assay validation of ganoderic acid $\mathrm{A}$ and $\mathrm{F}$ were $105.16 \%$ and $101.38 \%$, respectively, whereas those of interday of ganoderic acids $\mathrm{A}$ and $\mathrm{F}$ were $103.01 \%$ and $99.35 \%$, respectively. The mean recovery of ganoderic acids $\mathrm{A}$ and $\mathrm{F}$ including IS were $73.51 \%, 89.52 \%$, and $72.66 \%$, respectively.

\subsection{Data Analysis and Statistical Methods}

2.7.1. Pharmacokinetic Parameters. The maximum plasma concentration $\left(C_{\max }, \mathrm{ng} / \mathrm{mL}\right)$ and time to reach maximum concentration $\left(T_{\max }, \mathrm{h}\right)$ of ganoderic acids $\mathrm{A}$ and $\mathrm{F}$ were evaluated directly by visual inspection of each subject's plasma concentration-time profile. The area under the concentration-time curve from administration to $8 \mathrm{~h}$ and to infinity $\left(\mathrm{AUC}_{0-8}\right.$ and $\left.\mathrm{AUC}_{0-\infty}, \mathrm{ng} \cdot \mathrm{h} / \mathrm{mL}\right)$ as well as elimination half-life $\left(t_{1 / 2}, \mathrm{~h}\right)$, were determined by non-compartmental analysis. The slope of the terminal log-linear portion of the concentration-time profile was determined by least-squares regression analysis and used as the elimination rate constant $\left(K_{e}\right)$. The elimination $t_{1 / 2}$ was calculated from the ratio of $0.693 / K_{e}$. The AUC from time zero to the last quantifiable point $\left(\mathrm{AUC}_{0-8}\right)$ was calculated by using the trapezoidal rule and the extrapolated AUC from time $t$ to infinity $\left(\mathrm{AUC}_{t-\infty}\right)$ was determined as $C_{t} / K_{e}$. Total AUC was the sum of $\mathrm{AUC}_{0-8}+\mathrm{AUC}_{8-\infty}$. The calculation was performed by using the Topfit software version 2.0 for personal computer.

2.7.2. Statistical Analysis. The pharmacokinetic parameters were presented as mean \pm standard deviation (SD). The differences in the mean values of $C_{\max }, T_{\max }, t_{1 / 2}, \mathrm{AUC}_{0-8}$, and $\mathrm{AUC}_{0-\infty}$ between fasting and fed conditions were analyzed by using paired Student's $t$-test and were considered statistically significant if $P<0.05$.

\section{Results}

The demographic characteristics and means of clinical laboratory data of 12 subjects enrolled in the study are shown 
TABLE 1: The demographic characteristics and clinical laboratory data of 12 subjects enrolled in the study.

\begin{tabular}{|c|c|c|c|}
\hline Parameters & Mean \pm SD & Range & Normal values \\
\hline Age (y) & $26.83 \pm 4.86$ & $20-33$ & \\
\hline Weight $(\mathrm{kg})$ & $58.38 \pm 7.29$ & $48.5-74.0$ & \\
\hline Height (m) & $1.69 \pm 0.06$ & $1.60-1.78$ & \\
\hline BMI $\left(\mathrm{kg} / \mathrm{m}^{2}\right)$ & $20.51 \pm 1.97$ & $18.25-23.36$ & $18-25$ \\
\hline \multicolumn{4}{|l|}{ Laboratory data } \\
\hline Hemoglobin $(g / L)$ & $145.50 \pm 6.49$ & $130-157$ & $130-180$ \\
\hline Hematocrit (L/L) & $0.45 \pm 0.02$ & $0.43-0.48$ & $0.40-0.54$ \\
\hline $\mathrm{WBC}\left(\times 10^{9} / \mathrm{L}\right)$ & $7.93 \pm 1.83$ & $5.6-11.0$ & $4.4-11.0$ \\
\hline Platelets on smear & Adequate & - & Adequate \\
\hline BUN (mg/dL) & $13.17 \pm 1.95$ & $10-17$ & $8.4-21$ \\
\hline Creatinine (mg/dL) & $1.08 \pm 0.11$ & $0.9-1.3$ & $0.8-1.3$ \\
\hline SGOT (U/L) & $21.58 \pm 4.54$ & $16-30$ & $0-37$ \\
\hline SGPT (U/L) & $23.50 \pm 9.13$ & $13-39$ & $0-41$ \\
\hline $\operatorname{ALP}(\mathrm{U} / \mathrm{L})$ & $47.50 \pm 11.02$ & $30-64$ & $53-128$ \\
\hline Total bilirubin $(\mathrm{mg} / \mathrm{dL})$ & $0.42 \pm 0.23$ & $0.2-0.9$ & $0.1-1.2$ \\
\hline
\end{tabular}

BMI: body mass index; WBC: white blood cell; BUN: blood urea nitrogen; SGOT: serum glutamic oxaloacetic transaminase; SGPT: serum glutamic pyruvic transaminase; ALP: alkaline phosphatase.

in Table 1. All subjects completed the study protocol. On the basis of medical history, physical examination and laboratory investigation, none of the subjects showed any evidence of neurological, pulmonary, kidney, liver, or cardiovascular diseases.

The mean plasma concentration-time curves of ganoderic acid A at various sampling times from 12 subjects after a single oral administration of 3,000 mg of MG2FBWE under a fasting or fed condition are presented in Figure 3. That of ganoderic acid $\mathrm{F}$ under a fasting condition is presented in Figure 4. However, the mean plasma ganoderic acid $\mathrm{F}$ concentration-time curve under a fed condition is not shown due to insufficient data for calculation since plasma ganoderic acid $\mathrm{F}$ concentrations that are higher than the LLOQ were detected only in 2 out of 12 subjects. In one subject, the concentrations of 0.59 and $0.50 \mathrm{ng} / \mathrm{mL}$ were found at $2.50 \mathrm{~h}$ and $3.00 \mathrm{~h}$ after MG2FB-WE administration, respectively, whereas the concentration of $0.56 \mathrm{ng} / \mathrm{mL}$ was found at $3.50 \mathrm{~h}$ after dosing in another subject.

The pharmacokinetic parameters of ganoderic acids $\mathrm{A}$ and $\mathrm{F}\left(C_{\max }, T_{\max }, t_{1 / 2}, \mathrm{AUC}_{0-8}\right.$, and $\left.\mathrm{AUC}_{0-\infty}\right)$ following a single oral administration of $3,000 \mathrm{mg}$ of MG2FB-WE under a fasting or fed condition are presented in Table 2. Under a fasting condition, both ganoderic acids reached their $T_{\max }$ at approximately $30 \mathrm{~min}$. Ganoderic acids $\mathrm{A}$ and $\mathrm{F}$ had a very short elimination $t_{1 / 2}$ of $37.20 \mathrm{~min}$ and $28.80 \mathrm{~min}$, respectively. Food significantly decreased $C_{\max }$ as well as delayed $T_{\max }$ and $t_{1 / 2}$, but did not affect the extent $\left(\mathrm{AUC}_{0-8}\right.$ and $\mathrm{AUC}_{0-\infty}$ ) of ganoderic acid $\mathrm{A}$. However, since the plasma ganoderic acid $\mathrm{F}$ concentrations at any time points under a fed condition were below the LLOQ in most of the enrolled subjects, the pharmacokinetic parameters such as $C_{\max }, T_{\max }$, $t_{1 / 2}, \mathrm{AUC}_{0-8}$ including $\mathrm{AUC}_{0-\infty}$ were not be determined and therefore were not be statistically compared with those under a fasting condition.

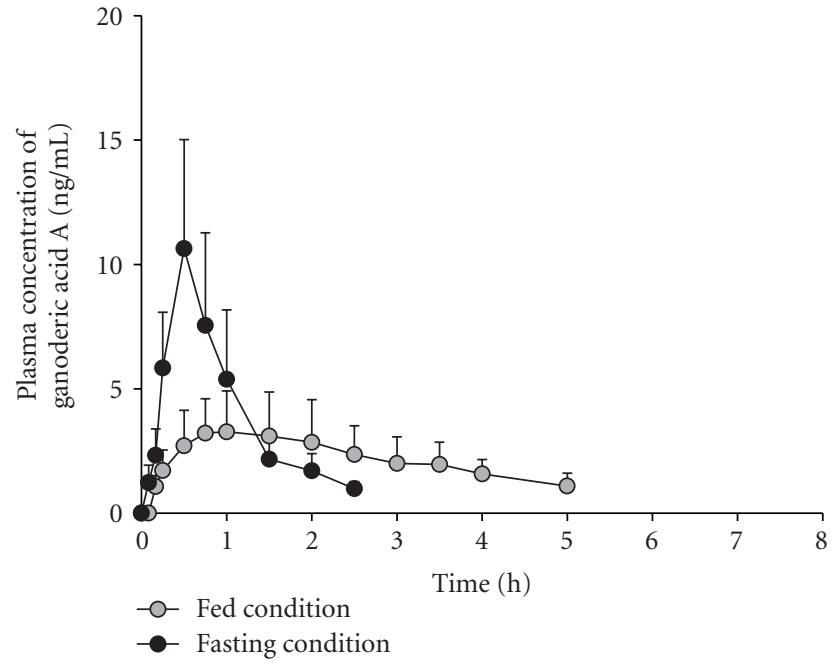

FIGURE 3: Mean plasma ganoderic acid A concentration-time curves after a single oral dose of MG2FB-WE under a fasting or fed condition.

\section{Discussion}

This is the first report on the pharmacokinetic study of ganoderic acids $\mathrm{A}$ and $\mathrm{F}$ after a single oral administration of MG2FB-WE in healthy Thai male volunteers. Since the study design of this pharmacokinetic study was similar to that of bioequivalence testing, the minimum number of 12 subjects were enrolled in the study according to the guideline on investigation of bioequivalence [16]. Additionally, a twophase crossover study was conducted in order to minimize subject variability between fasting and fed conditions.

The MG2FB-WE used in our pharmacokinetic study is currently under intensive investigation at the Faculty 


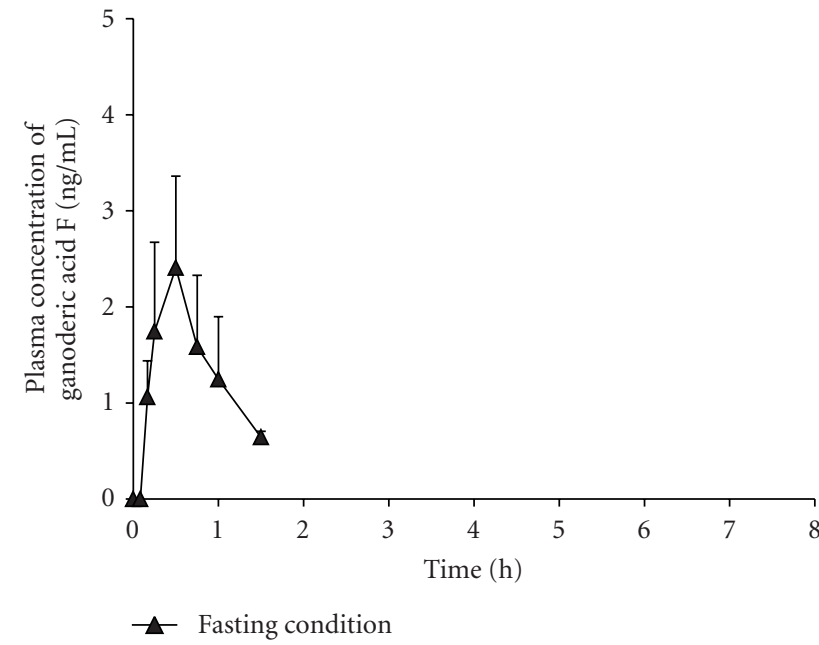

Figure 4: Mean plasma ganoderic acid F concentration-time curve after a single oral dose of MG2FB-WE under a fasting condition (mean plasma ganoderic acid $\mathrm{F}$ concentration-time curve under a fed condition is not shown due to insufficient data for calculation).

of Medicine, CMU, for its efficacy in the treatment of advanced gynecologic and other advanced-stage cancers using a dosage of 3,000 mg twice daily $(6,000 \mathrm{mg} /$ day $)$ for 3 months. This dosage was selected in accordance to the study previously reported by Gao et al. [17] exhibiting that the oral administration of 5,400 mg/day of Ling Zhi extract for $12 \mathrm{wk}$ significantly enhances the immune responses in patients with advanced-stage cancers. Indeed, MG2FBWE used in the ongoing clinical trials was prepared as granular formulation dissolved in $200 \mathrm{~mL}$ of warm water before oral administration. This formulation has proved to be easier and more acceptable for the cancer patients to consume than other dosage forms, such as a single dose of 6 capsules $(500 \mathrm{mg} / \mathrm{capsule}$ ) each time. Therefore, a single dosage of 3,000 mg of MG2FB-WE in granular formulation was investigated in the present study based on the dosage and formulation used in the ongoing clinical trials mentioned above. In addition, the granular formulation was considered to be superior to other formulations (capsules and tablets) in this pharmacokinetic study because the granules are readily dissolved and absorbed without the necessity to evaluate for its dissolution and disintegration profiles, which are the major confounding factors during an absorptive phase.

The measurement of plasma ganoderic acids $\mathrm{A}$ and $\mathrm{F}$ was performed by using the LC-MS method due to its rapid (runtime of $20 \mathrm{~min}$ ), high specificity and sensitivity (LLOQ of $0.50 \mathrm{ng} / \mathrm{mL}$ ) in comparison to longer runtime (runtime of $60 \mathrm{~min}$ ) and lower sensitivity (LLOQ of $2.50 \mu \mathrm{g} / \mathrm{mL}$ ) by HPLC-UV $(252 \mathrm{~nm})$ technique in our preliminary experiments. The validation of LC-MS assay demonstrated validity in precision, accuracy as well as recovery following the US FDA guidance, thus showing the suitability of this method for analysis of ganoderic acids $\mathrm{A}$ and $\mathrm{F}$ in plasma samples.

According to plasma concentration-time curves under a fasting condition, ganoderic acids $\mathrm{A}$ and $\mathrm{F}$ could be detected in the plasma as early as $5-10 \mathrm{~min}$ after an oral administration and reached their $T_{\max }$ at approximately $30 \mathrm{~min}$. Both ganoderic acids $\mathrm{A}$ and $\mathrm{F}$ had a very short elimination $t_{1 / 2}$ of $37.20 \mathrm{~min}$ and $28.80 \mathrm{~min}$, respectively. These findings are in agreement with the previously reported pharmacokinetic parameters in animals that revealed rapid absorption and elimination of G. lucidum triterpenes as evidenced by a $T_{\max }$ value range from $18-110 \mathrm{~min}$ and elimination $t_{1 / 2}$ of 35-143 min [18-20]. AUC of ganoderic acids $\mathrm{A}$ and $\mathrm{F}$ were low in spite of large dose of Ling Zhi preparation containing relatively high contents of ganoderic acids A $(4253.40 \mu \mathrm{g})$ and $\mathrm{F}(642.75 \mu \mathrm{g})$ was administered. This data suggests low oral bioavailability of ganoderic acids $\mathrm{A}$ and $\mathrm{F}$, which was consistent to the bioavailability of approximately $10 \%$ of ganoderic acid A reported in previous studies [18]. Since the rate of drug absorption is almost always directly proportional to the extent of absorption, we therefore postulated that the relatively low oral bioavailability of ganoderic acids $\mathrm{A}$ and $\mathrm{F}$ could probably not result from the poor absorption from gastrointestinal tract because their absorption appeared to be very rapid. However, this poor oral bioavailability might be due to their extensive hepatic first-pass metabolism coupled with partial conversion of some triterpenes to their metabolites by intestinal bacteria as reported in rat feces, but not in plasma and urine [20]. Further studies should be investigated to identify the exact mechanisms involving in this low oral bioavailability.

It is well known that food may positively or negatively affect the rate and/or extent of the bioavailability of various drugs [21-23]. This study revealed that food caused a significant decrease in $C_{\max }$ and rate of absorption $\left(T_{\max }\right)$ of ganoderic acid $\mathrm{A}$, but not the extent (AUC) of absorption. Since it is established that most drugs are ordinarily absorbed from the small intestine and delayed gastric emptying will delay absorption of those drugs that are absorbed predominantly from the small intestine [21, 23], we postulated that food affected the rate but not the extent of ganoderic acid A absorption through slowing of gastric emptying. Indeed, many dietary factors, such as solid food, high-fat content, and high osmolarity, have been found to delay gastric emptying [21-23]. Nonetheless, concomitant food administration also significantly prolonged the $t_{1 / 2}$ of ganoderic acid A. This finding presumably resulted from the delayed ganoderic acid A absorption due to prolonged gastric emptying by food, yielding sustained plasma levels and distorted the terminal $t_{1 / 2}$ under a fed condition.

The absorption of ganoderic acid $\mathrm{F}$ was probably affected by food in the same manner as that of ganoderic acid A. Since the concentrations of ganoderic acid $\mathrm{F}$ were already low under a fasting condition, the effect of food would then impede the absorption to the point that its plasma concentrations were lower than the LLOQ. Its pharmacokinetic parameters, likewise, could not be assessed. Owing to the fact that food intake generally impairs the rate and/or extent of ganoderic acids and perhaps other triterpenes, we recommend that Ling Zhi preparations should be taken on an empty stomach whenever possible.

Several in vitro studies have demonstrated that cytotoxicity against various human cancer cell lines expressed as $\mathrm{IC}_{50}$ values are in the range of $9.47-26.50 \mu \mathrm{M}$ (approximately 
TABLE 2: Pharmacokinetic parameters of ganoderic acids A and F after a single oral administration of MG2FB-WE under a fasting or fed condition. ${ }^{\dagger}$

\begin{tabular}{lcccc}
\hline \multirow{2}{*}{ Parameters } & \multicolumn{2}{c}{ Ganoderic acid A } & \multicolumn{2}{c}{ Ganoderic acid F } \\
& Fasting condition & Fed condition & Fasting condition & Fed condition \\
\hline$C_{\max }(\mathrm{ng} / \mathrm{mL})$ & $10.99 \pm 4.02^{* *}$ & $3.84 \pm 1.56$ & $2.57 \pm 0.91$ & $\mathrm{ND}$ \\
$T_{\max }(\mathrm{h})$ & $0.54 \pm 0.18^{*}$ & $1.67 \pm 0.88$ & $0.52 \pm 0.13$ & $\mathrm{ND}$ \\
$t_{1 / 2}(\mathrm{~h})$ & $0.62 \pm 0.17^{*}$ & $1.34 \pm 0.65$ & $0.48 \pm 0.22$ & $\mathrm{ND}$ \\
$\mathrm{AUC}_{0-8}(\mathrm{ng} \cdot \mathrm{h} / \mathrm{mL})$ & $9.58 \pm 4.08$ & $8.75 \pm 5.32$ & $1.81 \pm 0.76$ & $\mathrm{ND}$ \\
$\mathrm{AUC}_{0-\infty}(\mathrm{ng} \cdot \mathrm{h} / \mathrm{mL})$ & $10.53 \pm 4.32$ & $11.02 \pm 5.54$ & $2.42 \pm 0.93$ & $\mathrm{ND}$ \\
\hline
\end{tabular}

${ }^{\dagger}$ Data represents mean $\pm \mathrm{SD}$.

${ }^{*} P<0.01,{ }^{*} P<0.001$ denote statistically significant as compared to a fed condition according to paired Student's $t$-test.

ND: cannot be determined because the plasma ganoderic acid F concentrations at any time points were below the LLOQ in most of the enrolled subjects.

$4,900-13,700 \mathrm{ng} / \mathrm{mL}$ ) for ganoderic acid A [11] and 9.62$19.50 \mu \mathrm{M}$ (approximately $5,500-11,000 \mathrm{ng} / \mathrm{mL}$ ) for ganoderic acid $\mathrm{F}[11,13]$. These targeted concentrations are much higher than the mean $C_{\max }$ of $10.99 \pm 4.02 \mathrm{ng} / \mathrm{mL}$ for ganoderic acid A and $2.57 \pm 0.91 \mathrm{ng} / \mathrm{mL}$ for ganoderic acid $\mathrm{F}$ found in this study. Therefore, it is unlikely to achieve cytotoxic effects in vivo although a relatively highdose or multiple-dosage regimen of Ling Zhi extract is used. However, Ling Zhi is well documented to contain over 150 types of triterpenes [2,3], and many of them have been demonstrated to possess direct anticancer activity through different mechanisms of action for example, induction of cell cycle arrest and apoptosis [24, 25], inhibition of proliferation, migration, invasion, metastasis, and angiogenesis of carcinoma cell lines $[10,12,13,26]$. Therefore, in vivo anti-cancer activity might be exerted via synergistic effects among these triterpenes and with other biologically active compounds such as immunomodulatory protein, Ling Zhi8 [27, 28]. Additionally, polysaccharide fractions might also play some additional benefits through activation of an immune response against cancer $[29,30]$.

The major limitation of present study was the limited ability of the LC-MS technique to measure very low levels of ganoderic acid $\mathrm{F}$ in plasma samples, especially under a fed condition, because its plasma concentrations at any time points were lower than the LLOQ value of an analytical method, being unable to establish individual plasma concentration-time data and hence calculation for pharmacokinetic parameters. Therefore, a more sensitive analytical method (such as LC-MS/MS) or study using a Ling Zhi preparations containing high content of ganoderic acid $\mathrm{F}$ are suggested for the determination of human plasma ganoderic acid $\mathrm{F}$ and other triterpenes concentrations in future studies.

\section{Conclusion}

The pharmacokinetic profile of both ganoderic acids under a fasting condition was characterized by rapid absorption from the gastrointestinal tract ( $T_{\max }$ at approximately $30 \mathrm{~min}$ ) and a short elimination half-life $(<40 \mathrm{~min})$. Food significantly decreased $C_{\max }$ and delayed $T_{\max }$, but did not affect the extent $\left(\mathrm{AUC}_{0-8}\right.$ and $\left.\mathrm{AUC}_{0-\infty}\right)$ of ganoderic acid $\mathrm{A}$ absorption.
However, concomitant food intake markedly impeded both rate and extent of ganoderic acid $\mathrm{F}$ absorption.

\section{Abbreviations}

\begin{tabular}{|c|c|}
\hline $\mathrm{JC}_{0-}$ & $\begin{array}{l}\text { Area under the concentration-time curve from } \\
\text { administration to } 8 \mathrm{~h}\end{array}$ \\
\hline $\mathrm{AUC}_{0-\infty}:$ & $\begin{array}{l}\text { Area under the concentration-time curve from } \\
\text { administration and extrapolation to infinity }\end{array}$ \\
\hline $\max :$ & Maximum plasma concentration \\
\hline & Concentration at time $t$ \\
\hline & Elimination rate constant \\
\hline${ }_{2}:$ & Half-life \\
\hline & Time to reach maximum concer \\
\hline
\end{tabular}

\section{Acknowledgment}

The authors would like to acknowledge the Muang Ngai Special Agricultural Project under the patronage of Her Majesty Queen Sirikit, Chiang Mai for providing MG2FBWE. Furthermore, They also would like to express their special gratitude to Associate Professor Noppamas Soonthornchareonnon, Department of Pharmacognosy, Faculty of Pharmacy, Mahidol University for providing the reference standards of ganoderic acids A, F, and IS. Finally, grateful acknowledgement is made for financial support by the Thai Traditional Medical Knowledge Fund, Department for Development of the Thai Traditional and Alternative Medicine, Ministry of Public Health, Thailand. All authors have no conflict of interests.

\section{References}

[1] T. K. Yun, "Update from Asia. Asian studies on cancer chemoprevention," Annals of the New York Academy of Sciences, vol. 889, pp. 157-192, 1999.

[2] R. R. M. Paterson, "Ganoderma-A therapeutic fungal biofactory," Phytochemistry, vol. 67, no. 18, pp. 1985-2001, 2006.

[3] S. P. Wasser, "Reishi or Ling Zhi (Ganoderma lucidum)," in Encyclopedia Dietary Supplement, vol. 1, pp. 603-622, Marcel Dekker, New York, NY, USA, 1st edition, 2005.

[4] A. Morigiwa, K. Kitabatake, Y. Fujimoto, and N. Ikekawa, "Angiotensin converting enzyme-inhibitory triterpenes from Ganoderma lucidum," Chemical and Pharmaceutical Bulletin, vol. 34, no. 7, pp. 3025-3028, 1986. 
[5] K. Koyama, T. Imaizumi, M. Akiba et al., "Antinociceptive components of Ganoderma lucidum," Planta Medica, vol. 63, no. 3, pp. 224-227, 1997.

[6] M. Zhu, Q. Chang, L. K. Wong, F. S. Chong, and R. C. Li, "Triterpene antioxidants from Ganoderma lucidum," Phytotherapy Research, vol. 13, no. 6, pp. 529-531, 1999.

[7] S. Lee, S. Park, J. W. Oh, and C. H. Yang, "Natural inhibitors for protein prenyltransferase,” Planta Medica, vol. 64, no. 4, pp. 303-308, 1998.

[8] D. H. Kim, S. B. Shim, N. J. Kim, and I. S. Jang, "Beta-glucuronidase-inhibitory activity and hepatoprotective effect of Ganoderma lucidum," Biological and Pharmaceutical Bulletin, vol. 22, no. 2, pp. 162-164, 1999.

[9] G. J. Wang, Y. J. Huang, D. H. Chen, and Y. L. Lin, "Ganoderma lucidum extract attenuates the proliferation of hepatic stellate cells by blocking the PDGF receptor," Phytotherapy Research, vol. 23, no. 6, pp. 833-839, 2009.

[10] Y. Kimura, M. Taniguchi, and K. Baba, "Antitumor and antimetastatic effects on liver of triterpenoid fractions of Ganoderma lucidum: mechanism of action and isolation of an active substance," Anticancer Research A, vol. 22, no. 6, pp. 3309 3318, 2002.

[11] S. H. Guan, J. M. Xia, M. Yang, X. M. Wang, X. Liu, and D. A. Guo, "Cytotoxic lanostanoid triterpenes from Ganoderma lucidum," Journal of Asian natural products research, vol. 10, no. 7-8, pp. 705-710, 2008.

[12] J. Jiang, B. Grieb, A. Thyagarajan, and D. Sliva, "Ganoderic acids suppress growth and invasive behavior of breast cancer cells by modulating AP-1 and NF- $\kappa \mathrm{B}$ signaling," International Journal of Molecular Medicine, vol. 21, no. 5, pp. 577-584, 2008.

[13] Q. X. Yue, X. Y. Song, C. Ma et al., "Effects of triterpenes from Ganoderma lucidum on protein expression profile of HeLa cells," Phytomedicine, vol. 17, no. 8-9, pp. 606-613, 2010.

[14] A. Melander, "Influence of food on the bioavailability of drugs," Clinical Pharmacokinetics, vol. 3, no. 5, pp. 337-351, 1978.

[15] U.S. Department of Health and Human Services Food and Drug Administration, Center for Drug Evaluation and Research (CDER), and Center for Veterinary Medicine (CVM), Guidance for Industry Bioanalytical Method Validation, 2001.

[16] European Medicines Agency, Guideline on the Investigation of Bioequivalence, 2008.

[17] Y. Gao, S. Zhou, W. Jiang, M. Huang, and X. Dai, "Effects of ganopoly (a Ganoderma lucidum polysaccharide extract) on the immune functions in advanced-stage cancer patients," Immunological Investigations, vol. 32, no. 3, pp. 201-215, 2003.

[18] J. J. Gao, B. S. Min, T. Akao, M. R. Meselhy, N. Nakamura, and M. Hattori, "Enzyme immunoassay for the quatitative determination of ganoderic acid A from Ganoderma lucidum," Journal of Traditional Medicines, vol. 18, no. 4, pp. 154-160, 2001.

[19] J. Adamec, A. Jannasch, S. Dudhgaonkar, A. Jedinak, M. Sedlak, and D. Sliva, "Development of a new method for improved identification and relative quantification of unknown metabolites in complex samples: determination of a triterpenoid metabolic fingerprint for the in situ characterization of Ganoderma bioactive compounds," Journal of Separation Science, vol. 32, no. 23-24, pp. 4052-4058, 2009.

[20] Q. Zhang, F. Zuo, N. Nakamura, C. M. Ma, and M. Hattori, "Metabolism and pharmacokinetics in rats of ganoderiol $\mathrm{F}$, a highly cytotoxic and antitumor triterpene from Ganoderma lucidum," Journal of Natural Medicines, vol. 63, no. 3, pp. 304310, 2009.

[21] P. A. Winstanley and M. L. Orme, "The effects of food on drug bioavailability," British Journal of Clinical Pharmacology, vol. 28, no. 6, pp. 621-628, 1989.

[22] R. D. Toothaker and P. G. Welling, "The effect of food on drug bioavailability," Annual Review of Pharmacology and Toxicology, vol. 20, pp. 173-199, 1980.

[23] P. G. Welling, "Effects of food on drug absorption," Annual Review of Nutrition, vol. 16, pp. 383-416, 1996.

[24] N. H. Chen and J. J. Zhong, "Ganoderic acid Me induces $\mathrm{G}_{1}$ arrest in wild-type p53 human tumor cells while $G_{1} / S$ transition arrest in p53-null cells," Process Biochemistry, vol. 44, no. 8, pp. 928-933, 2009.

[25] C. H. Li, P. Y. Chen, U. M. Chang et al., "Ganoderic acid X, a lanostanoid triterpene, inhibits topoisomerases and induces apoptosis of cancer cells," Life Sciences, vol. 77, no. 3, pp. 252265, 2005.

[26] J. T. Xie, C. Z. Wang, S. Wicks et al., "Ganoderma lucidum extract inhibits proliferation of SW 480 human colorectal cancer cells," Experimental Oncology, vol. 28, no. 1, pp. 25-29, 2006.

[27] N. Miyasaka, H. Inoue, T. Totsuka, R. Koike, K. Kino, and H. Tsunoo, "An immunomodulatory protein, Ling Zhi-8, facilitates cellular interaction through modulation of adhesion molecules," Biochemical and Biophysical Research Communications, vol. 186, no. 1, pp. 385-390, 1992.

[28] L. G. van der Hem, J. A. van der Vliet, C. F. M. Bocken, K. Kino, A. J. Hoitsma, and W. J. M. Tax, "Ling Zhi-8: studies of a new immunomodulating agent," Transplantation, vol. 60, no. 5, pp. 438-443, 1995.

[29] Z. B. Lin, "Cellular and molecular mechanisms of immunomodulation by Ganoderma lucidum," Journal of Pharmacological Sciences, vol. 99, no. 2, pp. 144-153, 2005.

[30] Z. B. Lin and H. N. Zhang, "Anti-tumor and immunoregulatory activities of Ganoderma lucidum and its possible mechanisms," Acta Pharmacologica Sinica, vol. 25, no. 11, pp. 1387-1395, 2004. 


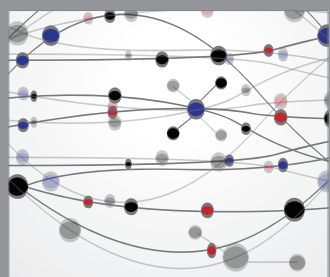

The Scientific World Journal
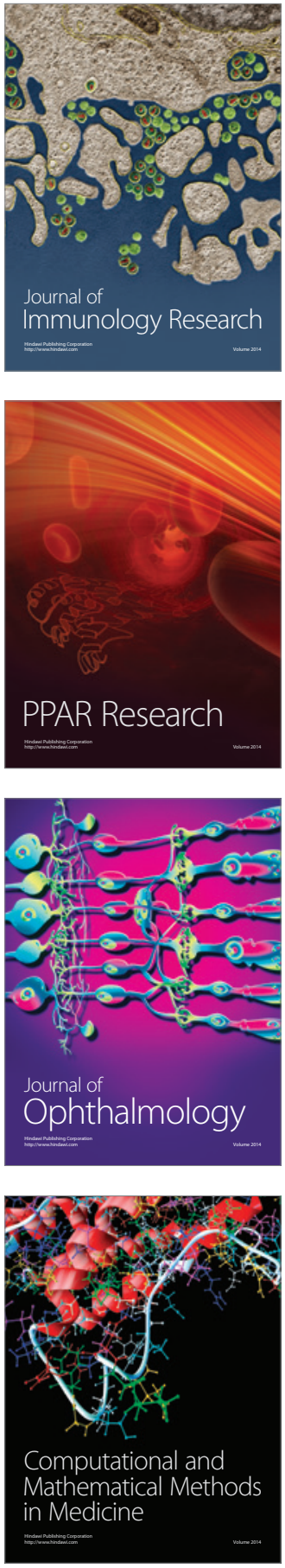

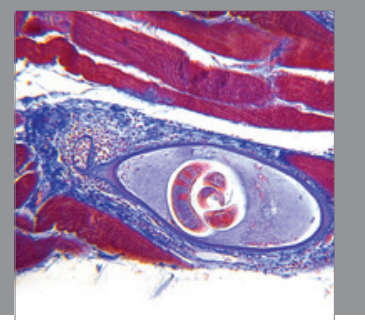

Gastroenterology

Research and Practice
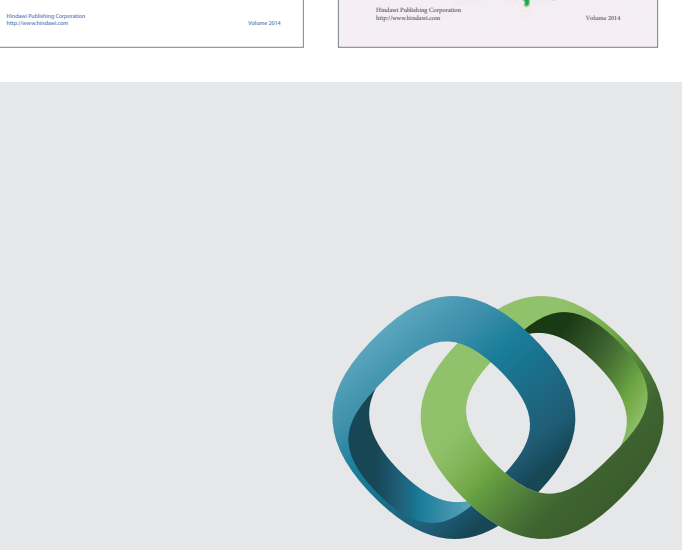

\section{Hindawi}

Submit your manuscripts at

http://www.hindawi.com
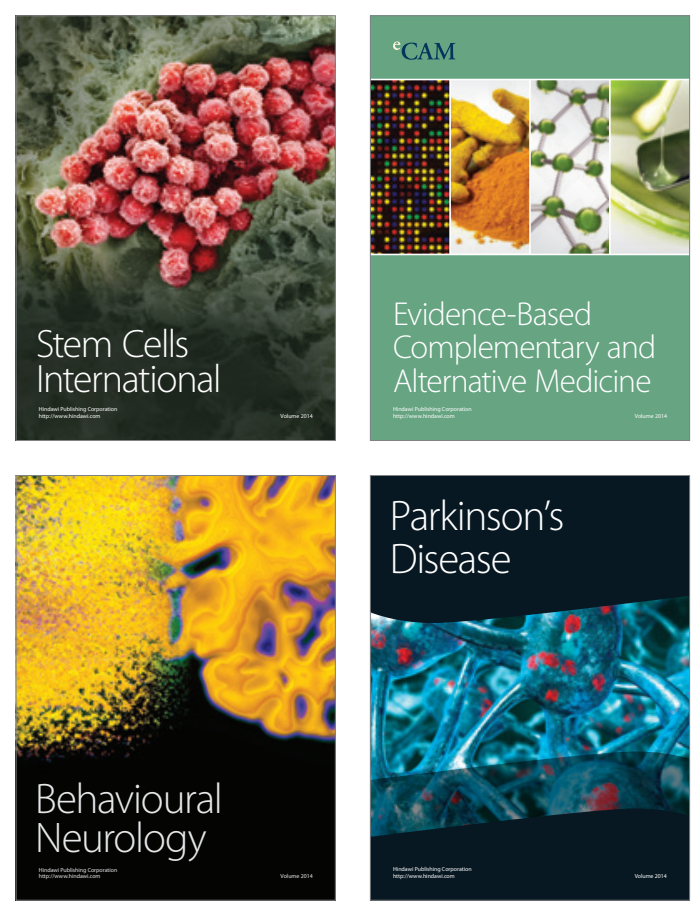

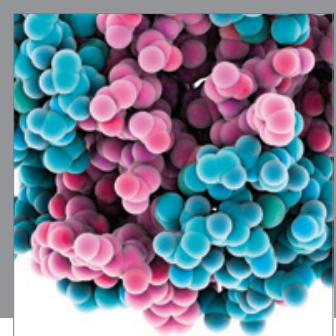

Journal of
Diabetes Research

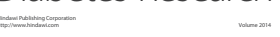

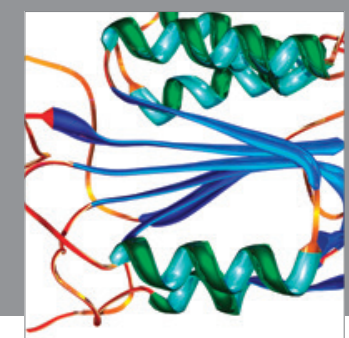

Disease Markers
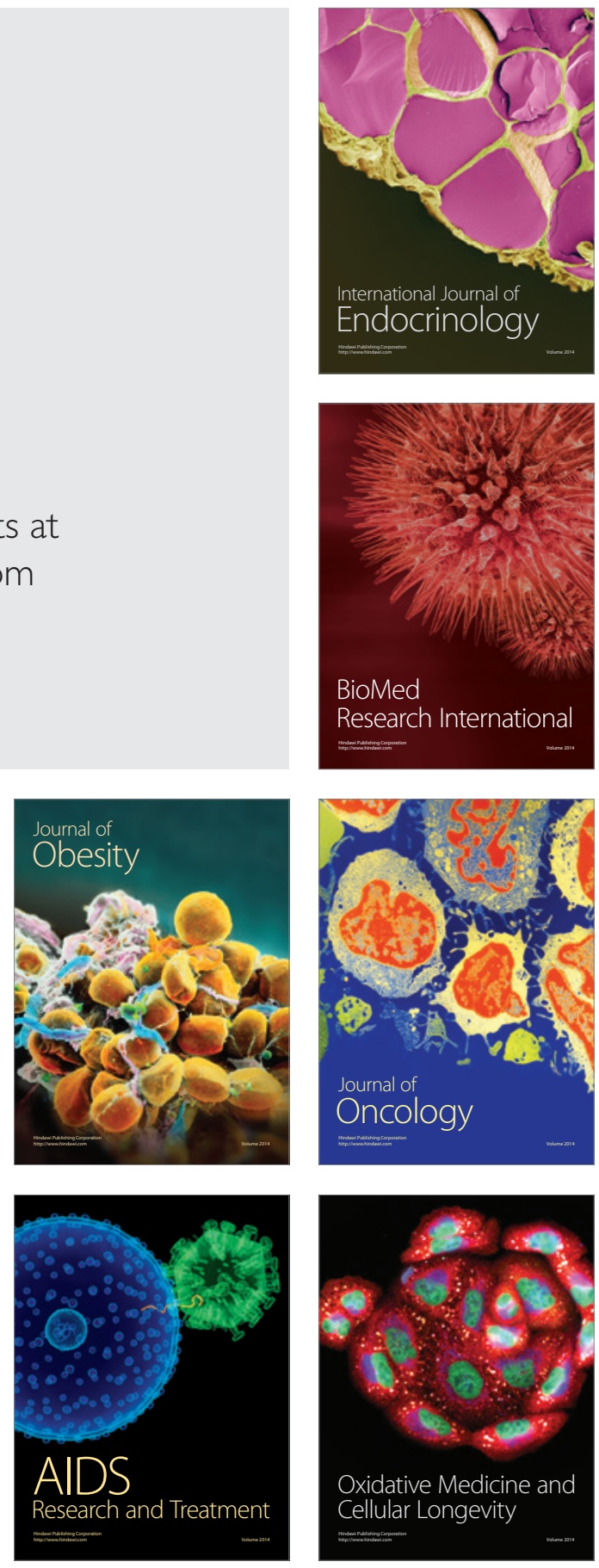